\title{
Diagnostic Workup of Small B Cell Lymphomas: A Laboratory Perspective
}

\author{
Kathryn Rizzo ${ }^{1}$ and Mehdi Nassiri² \\ ${ }^{1}$ Department of Pathology, Professional Pathology Services, 1 Science Court, Suite 200, Columbia, SC 29203, USA \\ ${ }^{2}$ Departments of Pathology and Laboratory Medicine, Indiana University School of Medicine, Indiana University Health Pathology \\ Laboratory, 350 W. 11th Street IUHPL 5044, Indianapolis, IN 46202, USA
}

Correspondence should be addressed to Mehdi Nassiri, mnassiri@iupui.edu

Received 11 August 2012; Accepted 25 September 2012

Academic Editor: Jan Delabie

Copyright ( $\odot 2012$ K. Rizzo and M. Nassiri. This is an open access article distributed under the Creative Commons Attribution License, which permits unrestricted use, distribution, and reproduction in any medium, provided the original work is properly cited.

Small B cell lymphoma is a morphological designation to a group of B cell lymphomas which are composed of a clonal population of small lymphoid cells. The subtypes of this category have diagnostically distinct characteristics and different clinical behaviors and treatment. Correct diagnosis and classification of these subsets depend on the integration of morphologic, immunophenotypic, and molecular genetic features. In this paper, differential diagnosis of this category of tumors and a practical approach based on biomarker evaluation are discussed.

\section{Introduction}

Diagnosis of lymphoid neoplasms has been drastically changed during the last three decades. It had transitioned over the years from a purely morphology-based approach [1] to a system that integrates immunologic and molecular biology findings. The current World Health Organization (WHO) classification [2] is based on a constellation of clinical, morphologic, immunophenotypic, and molecular genetic features. In the WHO classification, lymphoid malignancies are categorized based on their ontogeny to $\mathrm{B}$ or $\mathrm{T}$ cells. In the B lymphocyte group, two major categories are recognized: precursor and mature $B$ lymphocytes. Among mature B cell lymphoma neoplasms, those composed of small lymphoid cells are common and have overlapping features, thus definitive diagnosis may be challenging. Treatment and prognosis may vary from one subtype to the next, thus it is important to make the most definitive diagnosis as possible. In this paper we focus on the differential diagnosis of the common entities classified under the mature small B cell category which includes nodal, extranodal, and splenic marginal zone lymphoma (NMZL, ENMZL, SMZL), mantle cell lymphoma (MCL), chronic lymphocytic leukemia/small lymphocytic lymphoma (CLL/SLL), lymphoplasmacytic lymphoma (LPL), and low grade follicular lymphoma (FL). Other small B cell neoplasms that predominantly involve the blood and bone marrow (prolymphocytic leukemia and hairy cell leukemia) are not discussed.

The mature small B cell lymphomas comprise more than $30 \%$ of the non-Hodgkin lymphomas (FL grades I\&II, $16 \%$, ENMZL 8\%, SLL 7\%, MCL 6\%, NMZL 2\%, LPL 1\%). Based on their clinical course, lymphomas can also be further classified as either an indolent or aggressive disease. Low grade FL, MZL, and CLL/SLL show indolent behavior; in contrast MCL and high grade follicular lymphoma have an aggressive course. Indolent lymphomas are generally incurable with current standard therapeutic approaches and have a chronic course with repeated relapses despite therapy. Nevertheless, many of these patients survive many years with remarkably stable disease even in the absence of specific therapy. On the other hand, aggressive lymphomas usually have an acute presentation with more rapid progression. However, most aggressive lymphomas are potentially curable with combination chemotherapy. If complete remission is not achieved or there is relapse after an initial therapeutic response, survival is dismal. Therefore, these patients are 


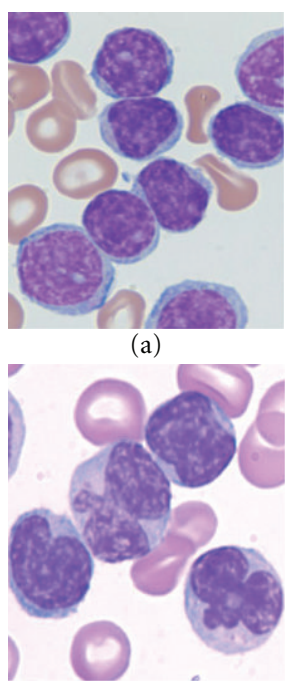

(b)

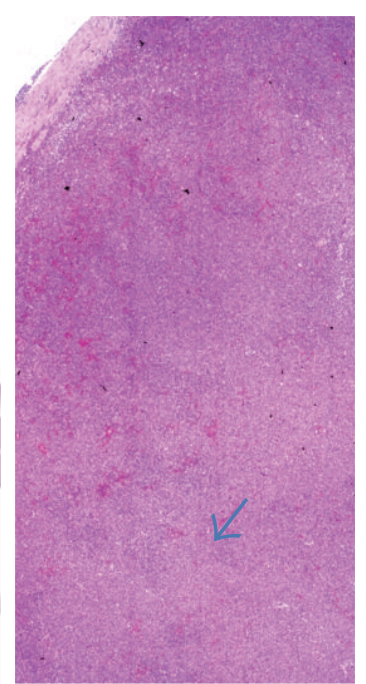

(c)

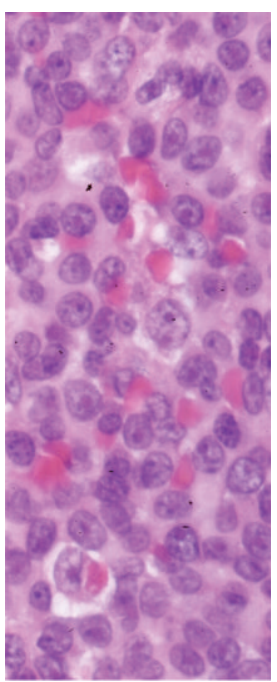

(d)

FIGURE 1: CLL/SLL. A Wright-Giemsa stained slide of CLL/SLL highlighting the typical small sized lymphocytes with mature chromatin (a). High power $(\times 1000)$ view of a Wright-Giemsa slide of CLL/SLL highlighting atypical morphology with multilobulated nuclei (b). Lymph node involved by CLL/SLL. The lymph node architecture is effaced by an atypical vaguely nodular lymphoid proliferation. Arrow points to a proliferation center (paler area), Hematoxylin-Eosin $\times 10$ (c). A high power view (Hematoxylin and Eosin $\times 1000)$ of the arrowed area in $(b)$, highlighting a proliferation center with scattered large prolymphocytes and paraimmunoblasts with larger nuclei and prominent nucleoli.

candidates for aggressive chemotherapy and stem cell transplantation [3].

\section{Chronic Lymphocytic Leukemia/Small Lymphocytic Lymphoma (CLL/SLL)}

B cell chronic lymphocytic leukemia (CLL) is the most common leukemia in the western world and is diagnosed with increasing frequency [4]. The median age of onset is 65 years; however, there is increasing incidence in younger patients. The male to female ratio is 1.5-2:1. Patients typically present with weakness, fatigue, and enlarged lymph nodes. CBC analysis shows a leukocytosis composed of an absolute lymphocytosis, with or without anemia or thrombocytopenia, and typically widespread lymphadenopathy. A number of patients, however, will be asymptomatic and found as an incidental finding on CBC or on excised lymph node. CLL and SLL are grouped together because they are indistinguishable, the difference being whether there is primarily involvement of the bone marrow and peripheral blood (CLL) versus primarily nodal-based disease (SLL). SLL without blood or bone marrow involvement is relatively uncommon; since most patients develop disseminated disease during the course of their ailment. In order to diagnose CLL in the absence of lymph node or extranodal tissue involvement, there must be more than $5 \times 10^{9} / \mathrm{L}$ monoclonal lymphocytes with the appropriate immunophenotype [5].

Peripheral blood shows a lymphocytosis composed of small-intermediate sized lymphoid cells which are similar in size to slightly larger than, a normal lymphocyte. The nuclei may be round to lobulated, contain coarse clumped chromatin, and lack nucleoli. Occasional cases of CLL/SLL may demonstrate atypical morphology (Figure 1) which includes cleaved or folded nuclei or plasmacytic morphology. This morphological atypia has been used to classify these cases as atypical CLL. Presence of more than 10\% atypical cells is associated with a more aggressive clinical behavior [6].

In lymph nodes, the architecture may be completely effaced by infiltrating cells resembling mature lymphocytes with coarse clumped chromatin. Pseudofollicular proliferation centers consisting of aggregates of prolymphocytes/ paraimmunoblasts (larger cells with prominent nucleoli) are useful diagnostic features [7]. However, sheeting out of large atypical lymphoid cells, resembling diffuse large B cell lymphoma, should prompt consideration for Richter's transformation. Richter's transformation into classical Hodgkin lymphoma is less commonly seen compared to diffuse large B cell lymphoma; however, it should contain Hodgkin/ReedSternberg cells seen in a classical Hodgkin lymphoma background milieu including plasma cells, eosinophils, immunoblasts, and histiocytes $[4,7,8]$.

Immunoglobulin heavy chain variable region $(\operatorname{IgH})$ mutational status and expression of ZAP-70 and CD38 are important prognostic factors. However, detection of $\operatorname{IgH}$ mutations is time consuming and expensive and therefore is not routinely performed. ZAP-70 and CD38 expression correlate with unmutated $\operatorname{IgH}$ and can be studied by immunohistochemistry or flow cytometry. Patients who express both markers have been shown to have a poor prognosis when compared to patients who lack expression of ZAP-70 and CD38 [9-11].

\section{Marginal Zone Lymphoma (MZL)}

The WHO classification defines three groups under marginal zone lymphomas (MZL): nodal, primary splenic, and 


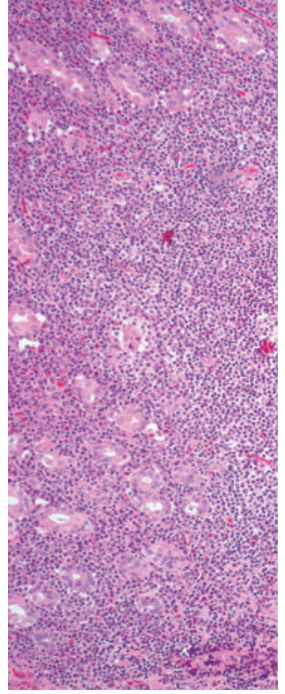

(a)

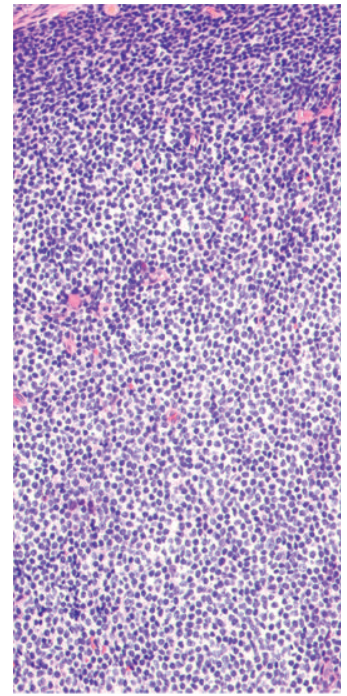

(b)

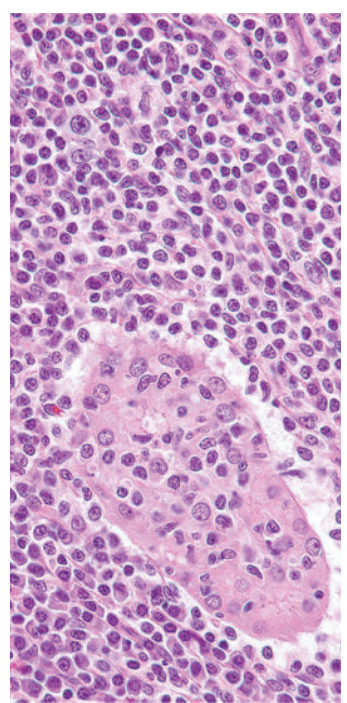

(c)

FIGURE 2: Extranodal marginal zone lymphoma. Low power $(\times 40)$ view of H\&E stained slide demonstrating ENMZL in a gastric biopsy. There is effacement of the epithelium by the atypical lymphoid infiltrate (a). Higher power view $(\times 200)$ demonstrates a monocytoid appearance to the atypical lymphoid cells which contain abundant pale cytoplasm (b). High power $(\times 500)$ view of the H\&E stained slide highlights a lymphoepithelial lesion (c).

extranodal marginal zone lymphoma of mucosa-associated lymphoid tissue (MALT lymphoma). In the past, MZL and the extranodal variant in particular were probably the most under-diagnosed mature B cell neoplasms $[12,13]$.

In the normal follicle the outermost area of the secondary follicle is considered the marginal zone. It is well developed and easily recognizable in the spleen, intra-abdominal lymph nodes, and mucosa-associated lymphoid tissue (MALT). The latter corresponds to Peyer's patches, which are present at birth (native MALT), or develops during life at different anatomic sites, such as the stomach, thyroid, salivary gland, lung, and skin. Their development is typically secondary to chronic inflammation sustained by an infective agent and/or an autoimmune condition (acquired MALT) [14, 15].

One of the characteristic cells of the marginal zone region is monocytoid B-cells. These cells are distinguished by their clear cytoplasm, mildly irregular nuclei, and inconspicuous nucleoli. They can be found in clusters within or around sinuses and in the interfollicular areas in various lymphadenitis. They can also surround benign follicles to produce a marginal zone pattern [16].

\subsection{Extranodal Marginal Zone Lymphoma (ENMZL). ENM-} ZLs (also called MALT lymphomas) are considered to arise from MALT usually in the setting of a chronic inflammatory process [17]. In the WHO classification, the term extranodal MZL consists of tumors composed of atypical lymphoid cells with either a centrocyte-like, plasmacytoid, small lymphoid, or monocytoid morphology. The majority of ENMZL cells are small to medium in size with varying degrees of nuclear atypia. They resemble typical centrocytes seen in a germinal center, small mature lymphocytes with no significant cytologic atypia, lymphocytes with plasma cell morphology, or monocytoid lymphocytes as described above. Plasma cells and scattered larger immunoblasts may be admixed. In glandular tissues, MZL cells invade epithelium and produce lymphoepithelial lesions that can be useful in histologic diagnosis (Figure 2). Marginal zone cells can also infiltrate the germinal centers of reactive follicles, a feature referred to as follicular colonization. MZL cells also displace the reactive plasma cells present in the gastric lamina propria $[18,19]$.

Best studied among this group is MZL of the stomach [20]. It has several hallmarks such as lymphoepithelial lesion formation and multicentricity. The role of Helicobacter pylori (HP) has been studied in detail in these tumors and consequently antibiotic therapy is now the cornerstone of treatment. Microbial agents have been also implicated in other types of ENMZL: chlamydia psittaci in ocular adnexa, borrelia burgdorferi in skin, and campylobacter jejuni in small intestinal ENMZL [21-23]. ENMZL is also associated with long-standing autoimmune disorders involving the thyroid and salivary glands.

3.2. Nodal Marginal Zone Lymphoma (NMZL). Diagnosis of NMZL is based on the exclusion of a primary extranodal or splenic tumor. NMZL is associated with advanced stage disease and lower 5-year overall and disease-free survivals compared to extranodal and splenic forms. Morphologically, there is effacement of the lymph node architecture with colonization of follicles and disruption of the follicular dendritic meshworks. The cells may contain a similar morphological appearance as seen in ENMZL. However, sheets of monocytoid appearing cells differentiate NMZL from lymph node involvement by lymphoplasmacytic lymphoma [24]. 


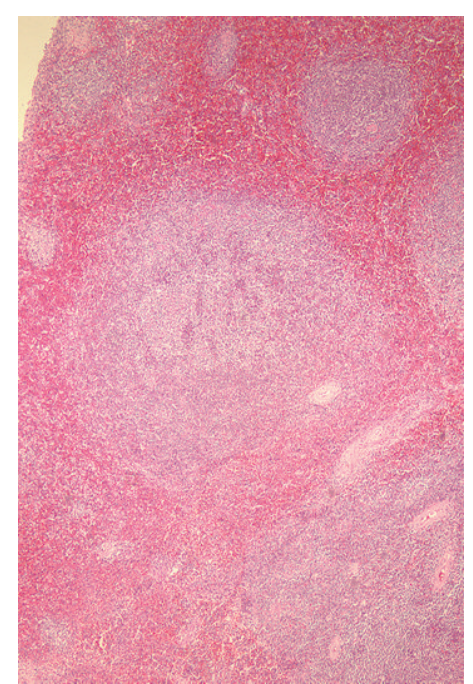

(a)

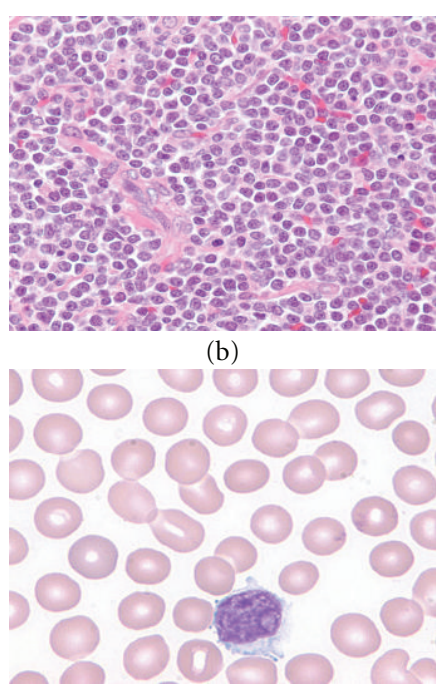

(c)

FIGURE 3: Splenic marginal zone lymphoma. Low power $(\times 20)$ view of Hematoxylin and Eosin stained slide demonstrating SMZL in a splenectomy specimen. There is involvement of the white pulp by an atypical lymphoid infiltrate expanding the marginal zone area (a). Higher power view $(\times 200)$ demonstrates a monocytoid and plasmacytoid appearance to the atypical lymphoid cells $(b)$. High power $(\times 1000)$ view of the Wright-Giemsa stained slide highlights a splenic villous lymphocyte containing cytoplasmic projections (c).

3.3. Splenic Marginal Zone Lymphoma (SMZL). SMZL is a rare disease characterized by splenomegaly and leukemic spread. In about $50 \%$ of cases, circulating neoplastic cells have cytoplasmic villous projections, hence the designation of splenic lymphoma with villous lymphocytes (SLVL). Low power evaluation of SMZL demonstrates a predominant nodular white pulp disease with extension into the red pulp (Figure 3). Morphologically and immunophenotypicaly, the cells are similar to ENMZL. Cytogenetics and molecular studies have shown that SMZL is a heterogeneous tumor $[25,26]$.

\section{Lymphoplasmacytic Lymphoma (LPL)}

Lymphoplasmacytic lymphoma (LPL) occurs in adults and may occur in younger patients associated with a familial predisposition [2]. Most cases present with bone marrow involvement and resultant symptomatology such as weakness and fatigue secondary to anemia. Lymph nodes, extranodal locations, spleen, liver, and peripheral blood may also be involved. Most cases present with a serum paraprotein which in a majority of the cases is IgM. Waldenstrom macroglobulinemia is characterized by LPL involving the bone marrow and an IgM monoclonal gammopathy. Due to the size of the IgM paraprotein complex a third of the patients may have hyperviscosity syndrome. Autoimmune disorders or cryoglobulinemia is seen in a lesser number of cases. Similar to MZL, LPL may be associated with amyloid deposition and crystal storing histiocytosis.

Lymphoplasmacytic lymphoma is composed of an admixture of small lymphocytes, plasmacytoid lymphocytes, and plasma cells. LPL typically involves the bone marrow in an intertrabecular/interstitial nodular, diffuse or vaguely nodular pattern with or without paratrabecular aggregates.
The bone marrow may also show increased numbers of mast cells (Figures 4(a) and 4(b)). Histologic patterns of lymph node involvement in LPL have been described [27]. The classic pattern demonstrates intact sinuses, with or without small residual follicles, and a monotonous lymphoplasmacytic proliferation in the intersinus area (Figures 4(c) and 4(d)). Another pattern includes a more polymorphous, vaguely nodular infiltrate. LPL may initially be present with lymph node involvement, and if present in a patient without a prior history may be difficult to differentiate from MZL with plasmacytic differentiation. In cases which have overlapping features of LPL and MZL, a final pathological diagnosis of small B-cell lymphoma with plasmacytic differentiation is acceptable.

LPL in a small number of cases can demonstrate transformation to an aggressive lymphoma and according to one report up to $13 \%$ of the cases progressed to a diffuse large B cell lymphoma [28]. Most of these cases presented clinically with profound cytopenias and a marked increase in the lactate dehydrogenase level, with bone marrow involvement as well as lymph node, skin, pleura, and maxilla involvement. Morphologically, these cases demonstrated sheets of transformed cells with a centroblastic or immunoblastic morphology and an increased proliferation rate. Residual LPL was also noted in most cases.

\section{Mantle Cell Lymphoma (MCL)}

MCL accounts for 5-10\% of all non-Hodgkin lymphomas. Mantle cell lymphoma has a median age in the 6th decade and affects males greater than females. MCL has one of the worst prognosis among all B-cell lymphomas. This disease is almost always widespread at the time of diagnosis with a high incidence of Waldeyer's ring involvement $[29,30]$. 


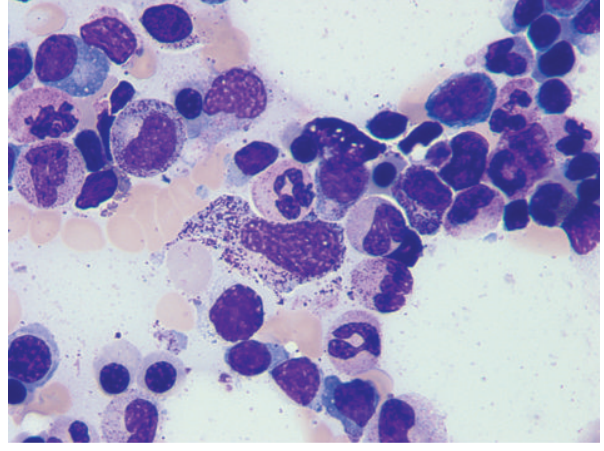

(a)

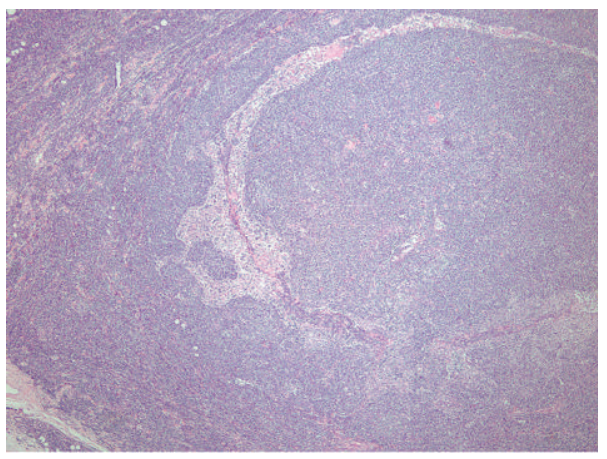

(c)

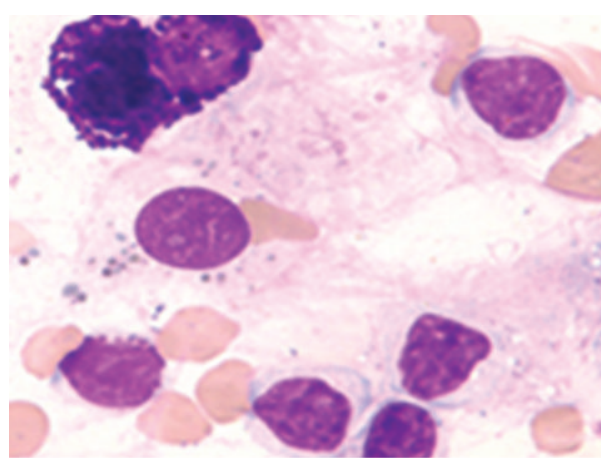

(b)

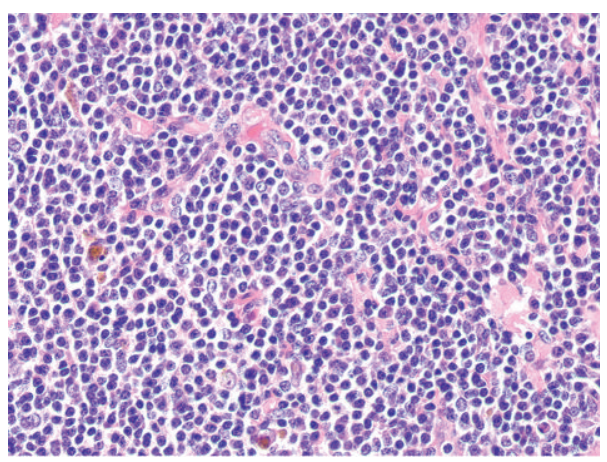

(d)

FIGURE 4: Lymphoplasmacytic lymphoma, Note admixed mast cells with normal and spindled morphology, Wright-Giemsa stain $\times 1000$ (a). Note admixed mast cells and lymphocytes, Wright-Giemsa stain $\times 1000$ (b). Lymph node involved by LPL with intact sinuses, Hematoxylin and Eosin $\times 40$ (c). High power demonstrates a lymphoplasmacytic infiltrate, Hematoxylin and Eosin $\times 500$ (d).

Morphologically, MCL most commonly presents with a diffuse or vaguely nodular pattern effacing the lymph node architecture. Nodularity may be very prominent and could lead to confusion with follicular lymphoma [31]. Occasionally a mantle zone pattern may also be seen in which the atypical lymphoid cells expand the mantle zone surrounding a reactive germinal center. Neoplastic lymphocytes are often small with irregular nuclei (Figure 5). The "blastoid" variant of MCL shows lymphoblast-like morphology with round nuclei, finely dispersed nuclear chromatin, and increased mitotic activity. These cases should be considered in the differential diagnosis of lymphoblastic lymphoma. The pleomorphic variant is composed of pleomorphic lymphoid cells, many large, with oval to irregular nuclei, pale cytoplasm and occasional prominent nucleoli (Figure 6).

\section{Follicular Lymphoma (FL)}

After diffuse large B-cell lymphoma, FL is the most common non-Hodgkin lymphoma in western countries. It occurs mainly in adults typically in the 6th decade and is more common in females. Patients typically present with progressive lymphadenopathy and advanced stage at diagnosis. Follicular lymphoma also has one of the most distinctive morphologic findings [32]. Proliferation of abnormal follicles is noted throughout the lymph node. There is little variation in size and shape of the follicles with little intervening normal lymphoid tissue. The abnormal follicles are cytologically monotonous with no tingible body macrophages. Polarization of normal follicles is also absent. Cells are either small-cleaved (centrocyte) or large non-cleaved (centroblast) (Figure 7). The relative proportion of these cells needs to be reported as part of the grading scheme for follicular lymphoma. There are interesting morphological variants including floral, plasmacytic differentiation, marginal zone B cell, and signet ring cell type [33-35].

Follicular lymphoma is generally divided into low and high grade based on high-power morphological evaluation. Follicular lymphoma is classified into low grade (grade 1-2) and high grade (grade 3 ) is based on the number of larger cells or centroblasts seen in a hematoxylin and eosin stained formalin fixed paraffin embedded tissue section. Follicular lymphoma grades 1 and 2 were grouped together in the 2008 WHO classification due to their similar clinical outcomes. Grade 1-2 cases are composed mostly of centrocytes. Larger centroblasts are less than 15 per high power field seen in 10 high power fields. Grade 3 has greater than 15 centroblasts and is further classified into $3 \mathrm{a}$ and $3 \mathrm{~b}$ with the later lacking residual centrocytes. Diffuse areas with a morphological appearance of a grade 3 are designated as diffuse large B cell lymphoma.

\section{Diagnostic Approach}

A standard hematoxylin and eosin-stained section prepared from an adequately fixed specimen can provide the 


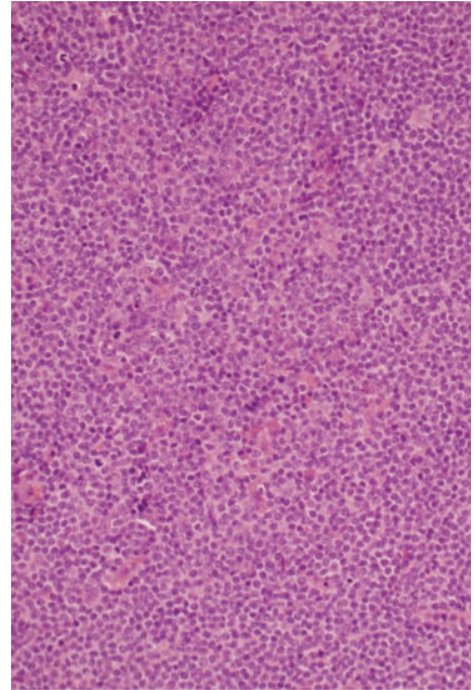

(a)

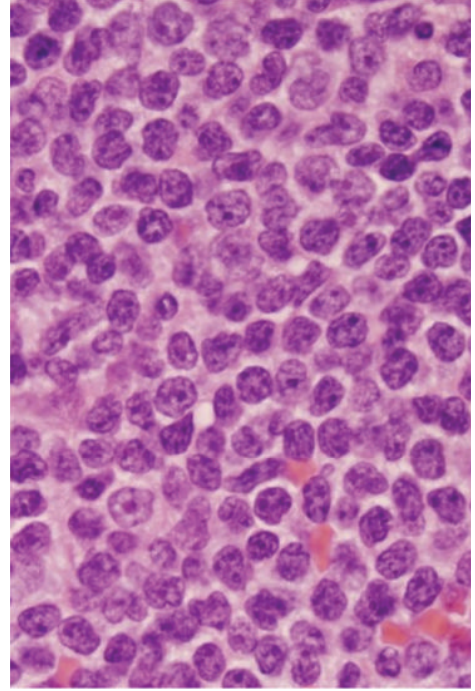

(b)

Figure 5: Mantle cell lymphoma. Diffuse infiltrate of small lymphocytes around atrophic germinal center (a), Hematoxylin and Eosin $\times 200$. Note nuclear irregularity (b), Hematoxylin and Eosin $\times 1000$.

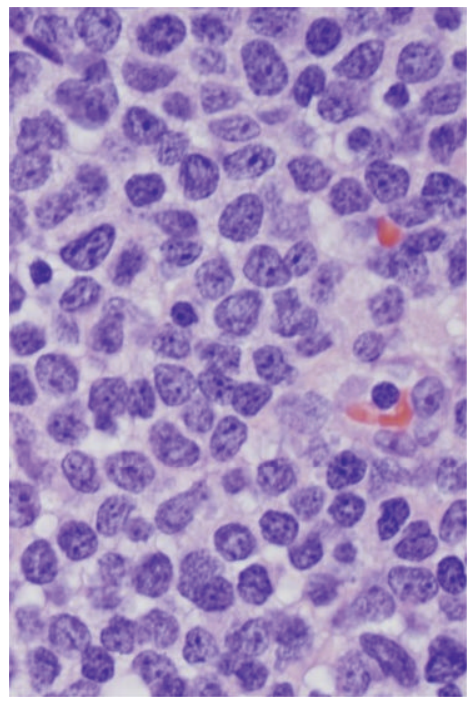

(a)

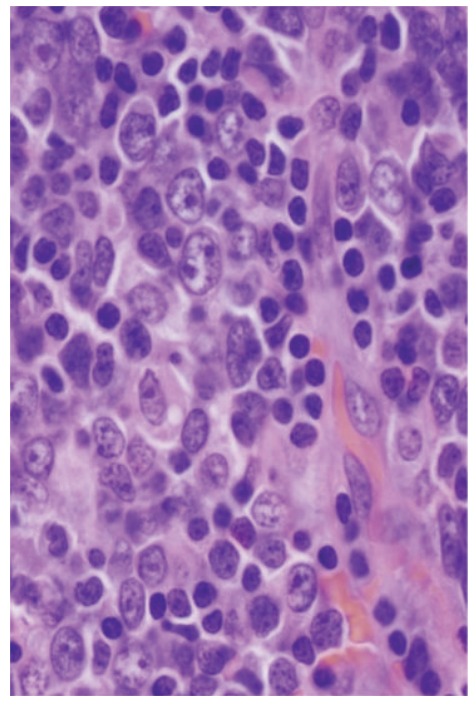

(b)

Figure 6: Mantle cell lymphoma variants. Blastoid variant shows diffuse infiltrate of cells with open chromatin similar to lymphoblastic lymphoma (a). Note difference in nuclear size and morphology in pleomorphic variant (b). Hematoxylin and Eosin $\times 1000$.

morphological framework for a differential diagnosis. A simple immunophenotypic panel can establish the diagnosis to a great extent. The combination of morphological and immunophenotypic evaluation will allow the differentiation between a reactive process and a lymphoid neoplasm, as well as, further classification of the lymphoma [36]. Consistency in performing a standard panel of markers prevents diagnostic error.

Morphology. The initial low power examination evaluates the degree of normal lymph node architecture effacement and the pattern of infiltration. Patterns of involvement include diffuse, nodular, and vaguely nodular. Although there are typical cytoarchitectural patterns described for each entity, they are not always present. Examination at higher power evaluates the composition of the infiltrate. Next one should ask if the infiltrate is composed of a monomorphic or polymorphic population of cells. High power examination evaluates cell size, type of morphological differentiation, and degree of atypia. An important step in morphologic evaluation is to estimate the size of the abnormal cell population. This can be achieved using a normal macrophage (or endothelial cell) nucleus as a size comparison (Figure 8). The nuclear size of the atypical lymphoid cells in the lesions 


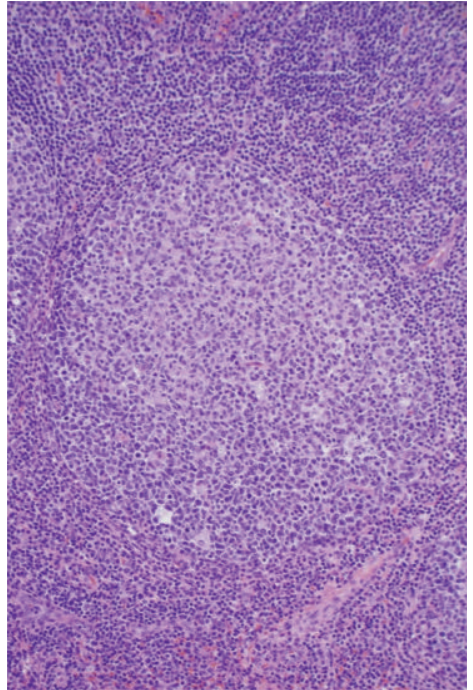

(a)

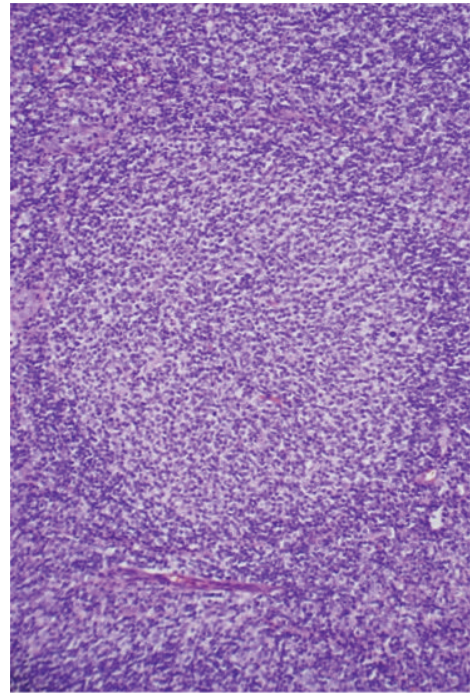

(b)

Figure 7: Normal follicle (a) versus follicular lymphoma (b). Note absence of light and dark zone and lack of tingible body macrophages in follicular lymphoma, Hematoxylin and Eosin $\times 100$.

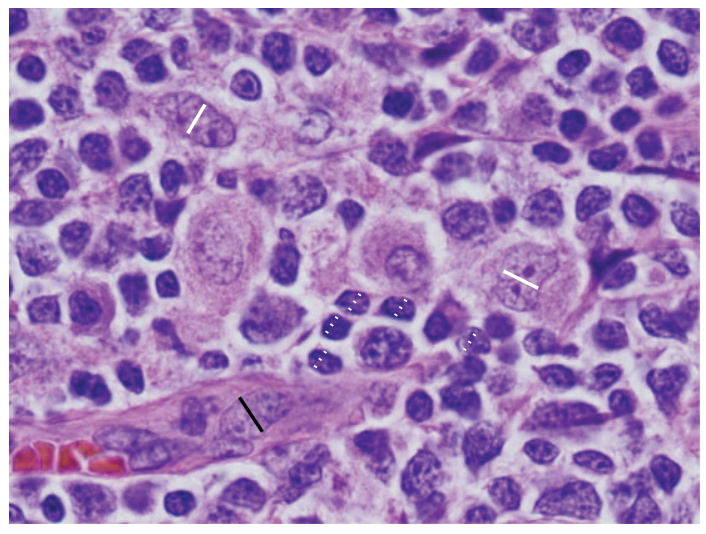

Figure 8: To estimate the lymphocyte size, the diameter of a macrophage nucleus (solid white line) or an endothelial cell (solid black line) should be compared with the adjacent lymphocytes (dotted white line), Hematoxylin-Eosin $\times 1000$.

discussed above is smaller than that of a macrophage or an endothelial cell. Next, one should decide on the degree of nuclear irregularity. SLL/CLL are composed mostly of cells with round nuclei similar to normal lymphocytes, while MCL and MZL have relatively irregular nuclei, and FL has the characteristic cleaved nuclei (centrocyte) that can be large and elongated. Characteristic morphologic findings are summarized in Table 1.

Fine needle aspiration can be used to identify an atypical cell population but lacks architecture and is thus not as informative as a core needle biopsy or excisional biopsy. For that reason, tissue biopsy is recommended for the initial diagnosis of a suspected lymphoproliferative disorder and this should be clearly conveyed to the oncologists and surgeons.
TABLE 1: Useful morphologic findings in differential diagnosis of small B cell lymphomas.

\begin{tabular}{llc}
\hline Diagnosis & Low power & Nuclei \\
\hline \multirow{2}{*}{ SLL } & $\begin{array}{l}\text { Diffuse infiltrate } \\
\text { Pseudofollicles } \\
\end{array}$ & Proliferation center \\
& Marginal zone expansion \\
MZL & $\begin{array}{l}\text { Interfollicular monocytoid cells } \\
\text { Follicular colonization }\end{array}$ & Irregular \\
& Diffuse or nodular infiltrate & \\
MCL & Mantle zone expansion & Irregular \\
& Atrophic germinal center & \\
FL & Monotonous follicles & Cleaved \\
\hline
\end{tabular}

Immunophenotyping. Both flow cytometry or paraffin block immunohistochemistry can be used to identify specific cell surface or intracellular protein expression. Flow cytometry has the advantage of simultaneous semiquantitative analysis of multiple markers as well as evaluating immunoglobulin light chain restriction in the determination of clonality. However, it requires fresh sample for cell suspension preparation, is relatively expensive, and cannot be correlated with cytoarchitectural findings. With advances in antigen retrieval techniques most antibodies can be successfully applied to paraffin blocks. Furthermore, immunohistochemistry (IHC) can easily identify a very minute population of abnormal cells [37].

An immunohistochemical panel should initially evaluate for the ontogeny of the atypical lymphoid infiltrate. B cell lineage is demonstrated by positive staining for CD20 (or other B cell markers such as PAX-5 and CD79a). CD3 should 


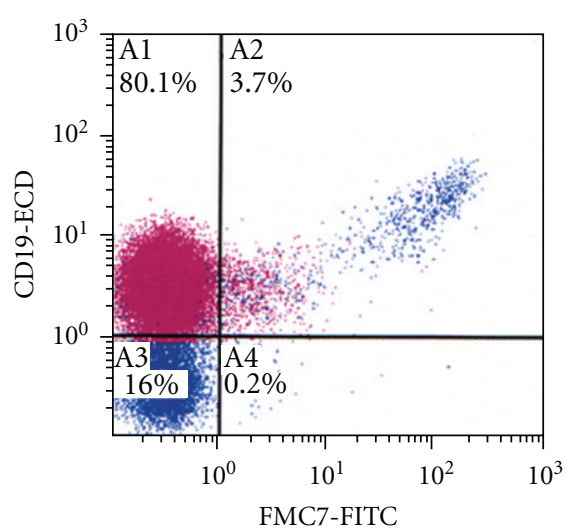

FMC7-FITC

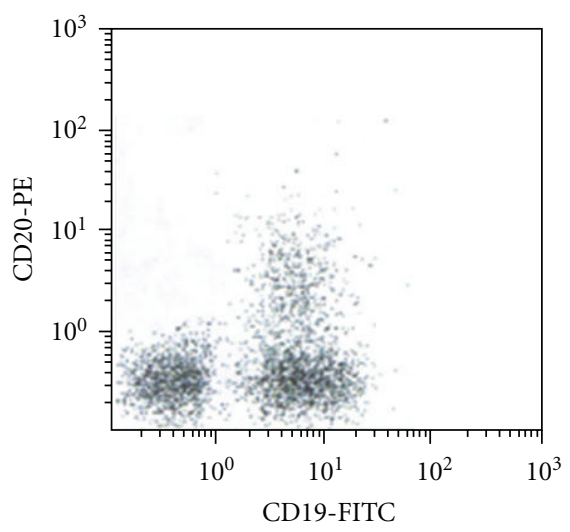

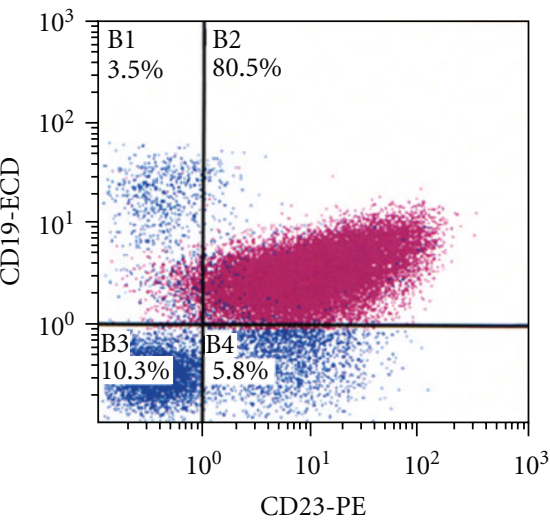

(a)

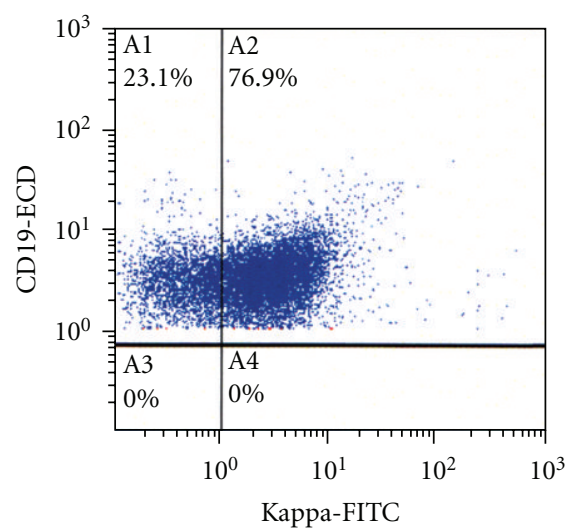

(b)
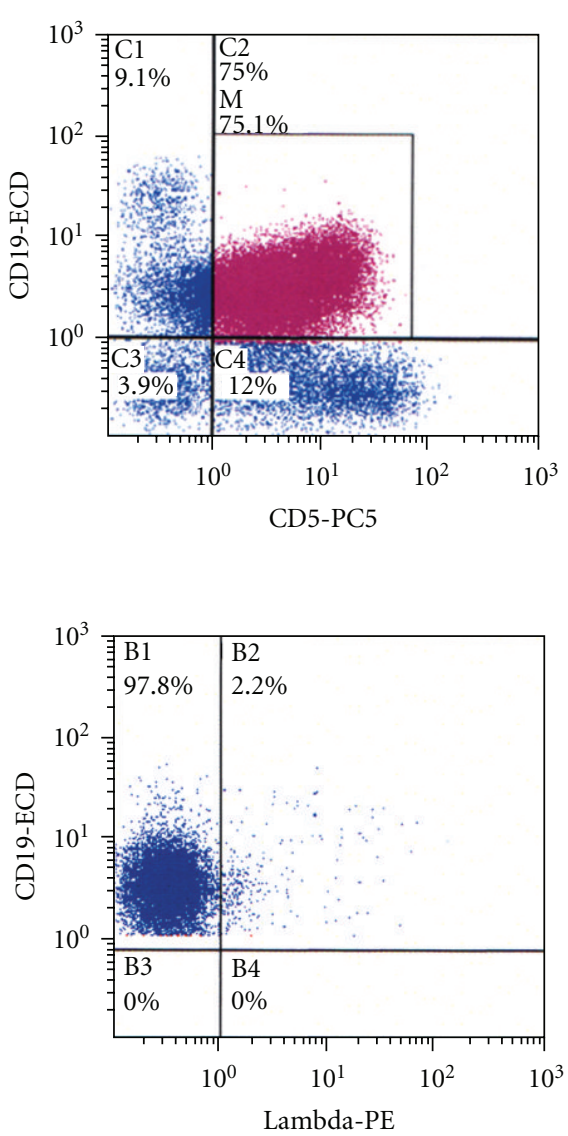

Figure 9: Typical flow cytometric Findings In CLL/SLL. (a) demonstrates a CD19 population (highlighted in red) which coexpresses CD23 and CD5. (b) demonstrates dim to negative coexpression of CD20 and dim expression of kappa light chains.

be included to evaluate for a neoplastic or nonneoplastic $\mathrm{T}$ cell population. A simple panel including CD5, CD10, CD23, and Cyclin D1 can resolve the diagnostic dilemma in most instances. These markers are useful in differentiating CLL/ SLL (CD5+, CD20+, CD23+) (Figure 9) and marginal zone lymphoma (CD5-, CD10-, CD20+, CD23+/-) from FL (CD5-, CD10+, CD20+) (Figure 10) or MCL (CD5+, CD20+, CD23-, Cyclin D1 +) (Figures 11 and 12). Bcl2 is commonly positive in all three lymphomas; however, it differentiates follicular lymphoma (bcl-2 positive) from follicular hyperplasia (bcl-2 negative). LPL and MZL have similar immunohistochemical staining patterns. It is important to note that a few cases of MZLs may present with CD5 positivity. This may become problematic in SMZL where CLL is in the differential diagnosis of a splenic lesion. Thus, correlation with laboratory findings (degree of lymphocytosis), morphological findings (plasmacytoid/monocytoid morphology), clinical findings (extensive lymphadenopathy), and cytogenetic findings is recommended. In LPL, flow cytometric analysis typically demonstrates a monoclonal B cell and a plasma cell population. The immunophenotype of the $\mathrm{B}$ cell population includes the B cell marker CD20 as well as MUM-1 and CD79a, both of which will also highlight the
Table 2: Practical immunohistochemistry panel for differential diagnosis of small B cell lymphoma (in addition to CD3, CD20, and assessment of clonality).

\begin{tabular}{lcccc}
\hline Diagnosis & CD5 & CD10/BCL6 & CD23 & Cyclin D1 \\
\hline CLL/SLL & + & - & + & - \\
MZL & - & - & - & - \\
MCL & + & - & - & + \\
FL & - & + & - & - \\
\hline
\end{tabular}

plasma cell component. The plasma cells are CD138 positive and usually positive for CD45 and CD19, unlike most plasma cell dyscrasias. In a majority of LPL cases, the plasma cells are PAX-5 positive versus negative staining seen in MZL and plasma cell dyscrasia. Immunohistochemistry for kappa and lambda light chain and immunoglobulin heavy chain (IgM, $\operatorname{IgG})$ can be useful in LPL cases.

We have summarized a practical phenotypic panel to correctly classify small B cell lymphocytic category in Table 2 . Some of the useful immunohistochemical makers are briefly discussed $[38,39]$. 


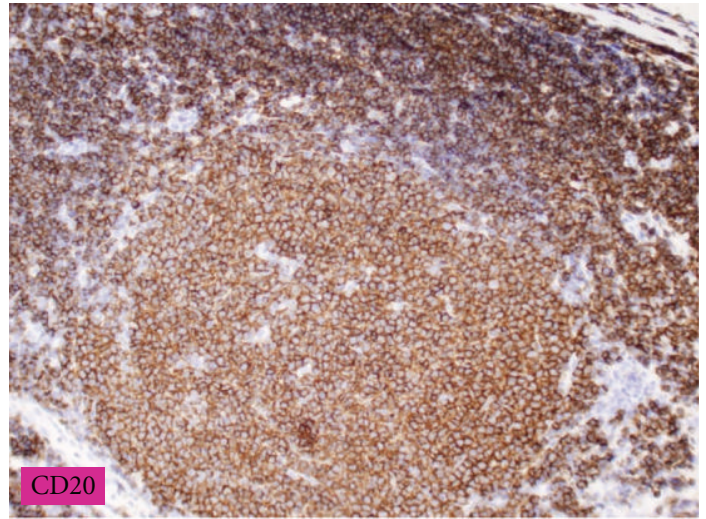

(a)

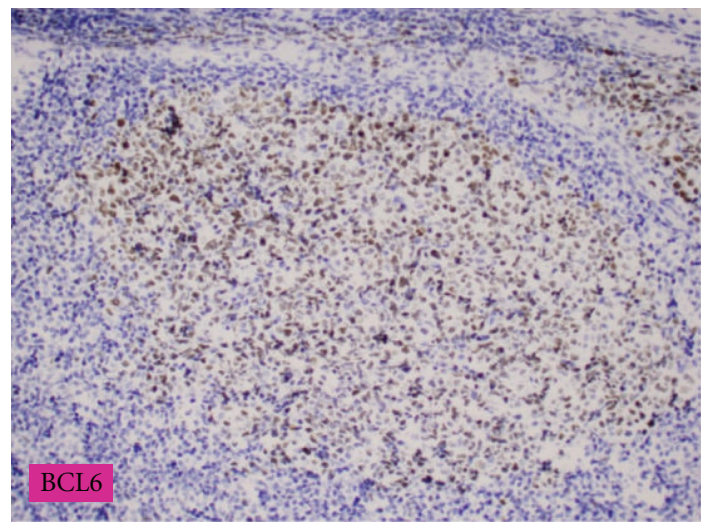

(c)

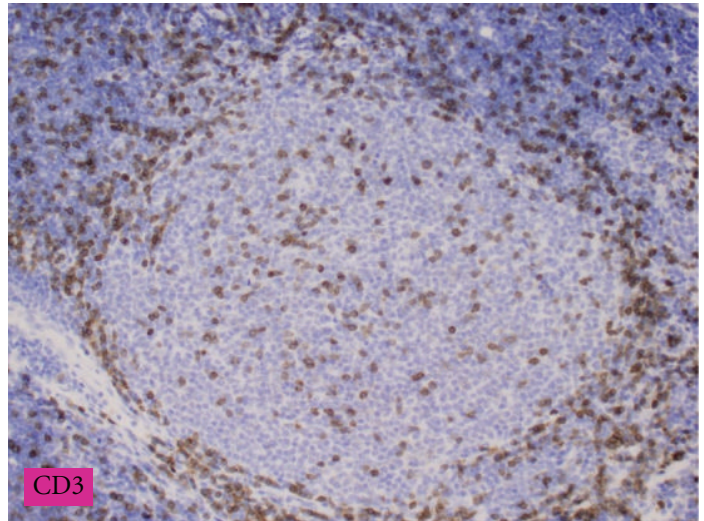

(b)

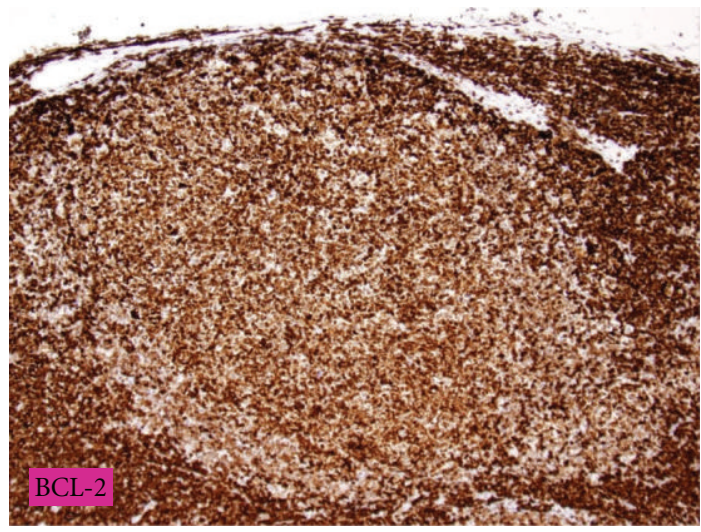

(d)

Figure 10: Follicular lymphoma immunohistochemistry. Atypical follicles are positive for CD20, BCL-6, and BCL-2, DAB chromogen, Hematoxylin $\times 200$.

CD3. Part of the $\mathrm{T}$ cell receptor complex is the CD3 protein. It is a useful pan $\mathrm{T}$ cell marker and is expressed from an early stage during $\mathrm{T}$ cell ontogeny.

CD5. CD5 is involved in T- and B-cell receptor signaling. It is a useful $\mathrm{T}$ cell marker and is present on post-thymic Tcells as well as thymocytes. It is also present on a small subset of normal B-cells (so-called B-1 lymphocytes) that may be increased in autoimmune disorders. CD5 is present on nearly all cases of SLL/CLL, and the great majority of MCLs. It is generally absent in other B-cell lymphomas.

CD10. Common acute lymphoblastic leukemia antigen (CALLA) is a cell-surface endopeptidase, positive in most cases of acute lymphoblastic lymphoma/leukemia of T- or Bcell type. It is also expressed in epithelial cells (liver canaliculi, renal tubules, and enterocytes). CD10 is positive in germinal center cells as well as neoplastic lymphoid cells in follicular lymphoma, Burkitt lymphoma, and a subset of diffuse large B-cell lymphoma. Follicular lymphoma is denoted as a CD10 positive B cell lymphoma; however, CD10 may be negative in up to $20 \%$ of the cases.

CD20. CD20 is involved in signal transduction and is expressed on the great majority of mature B-cell lymphomas.
This is a very useful "pan- $B$ " cell marker. Evaluation of $\mathrm{CD} 20$ expression has therapeutic importance. A humanized monoclonal antibody (Rituximab) against CD20 is now available for treatment of B-cell lymphomas expressing this molecule. Thus, CD20 expression is used as a criterion for administering Rituximab. CD20 can become negative after treatment with Rituximab, therefore, use of other B cell markers (PAX-5, CD79a) might be necessary in determining $B$ cell lineage.

CD23. CD23 is a low affinity receptor for IgE and has a role in cell-cell interactions. CD23 is expressed on a variety of cell types including activated B-cells and a subset of follicular dendritic cells, those in the light zone of the follicle center. CD23 expression is present in the majority of CLL/SLL cases, and its absence in MCL has diagnostic utility. In CLL/SLL, the level of expression may be variable and CD23 expression appears to be greater in the larger cells seen in proliferation centers. The lack of staining for follicular dendritic meshworks using CD21 or CD23 may be helpful in identifying diffuse areas in follicular lymphoma.

CD43. Also known as sialophorin is product of SPN gene and encoded a sialoglycoprotein found on the surface of thymocytes, T lymphocytes, monocytes, granulocytes, and 


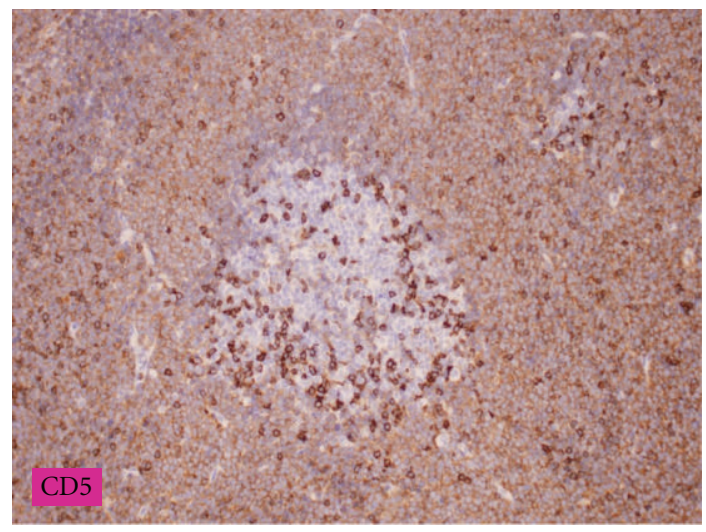

(a)

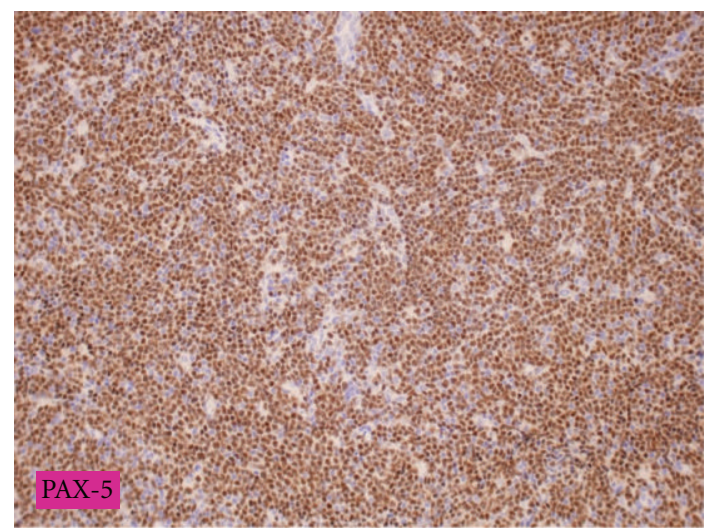

(c)

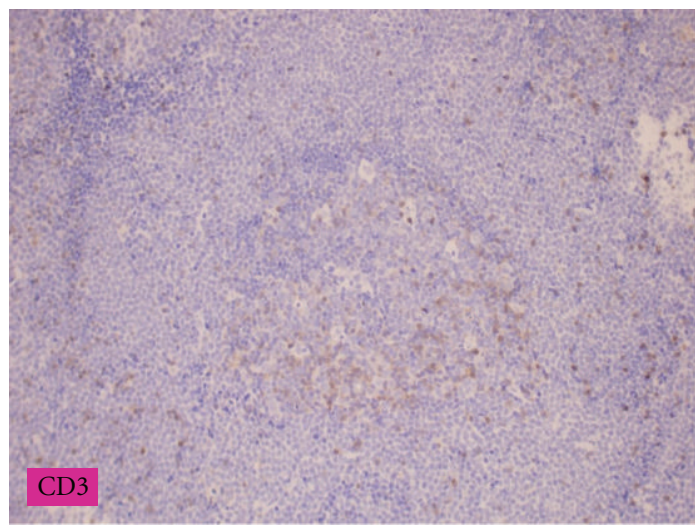

(b)

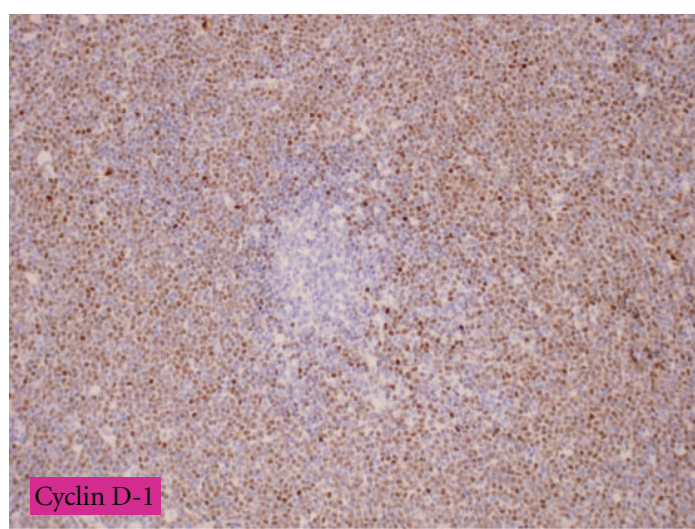

(d)

FIGURE 11: Typical immunohistochemical profile of mantle cell lymphoma. Expanded mantle zones are positive for CD5, PAX-5, and Cyclin D-1 and negative for CD3, DAB chromogen, Hematoxylin $\times 200$.
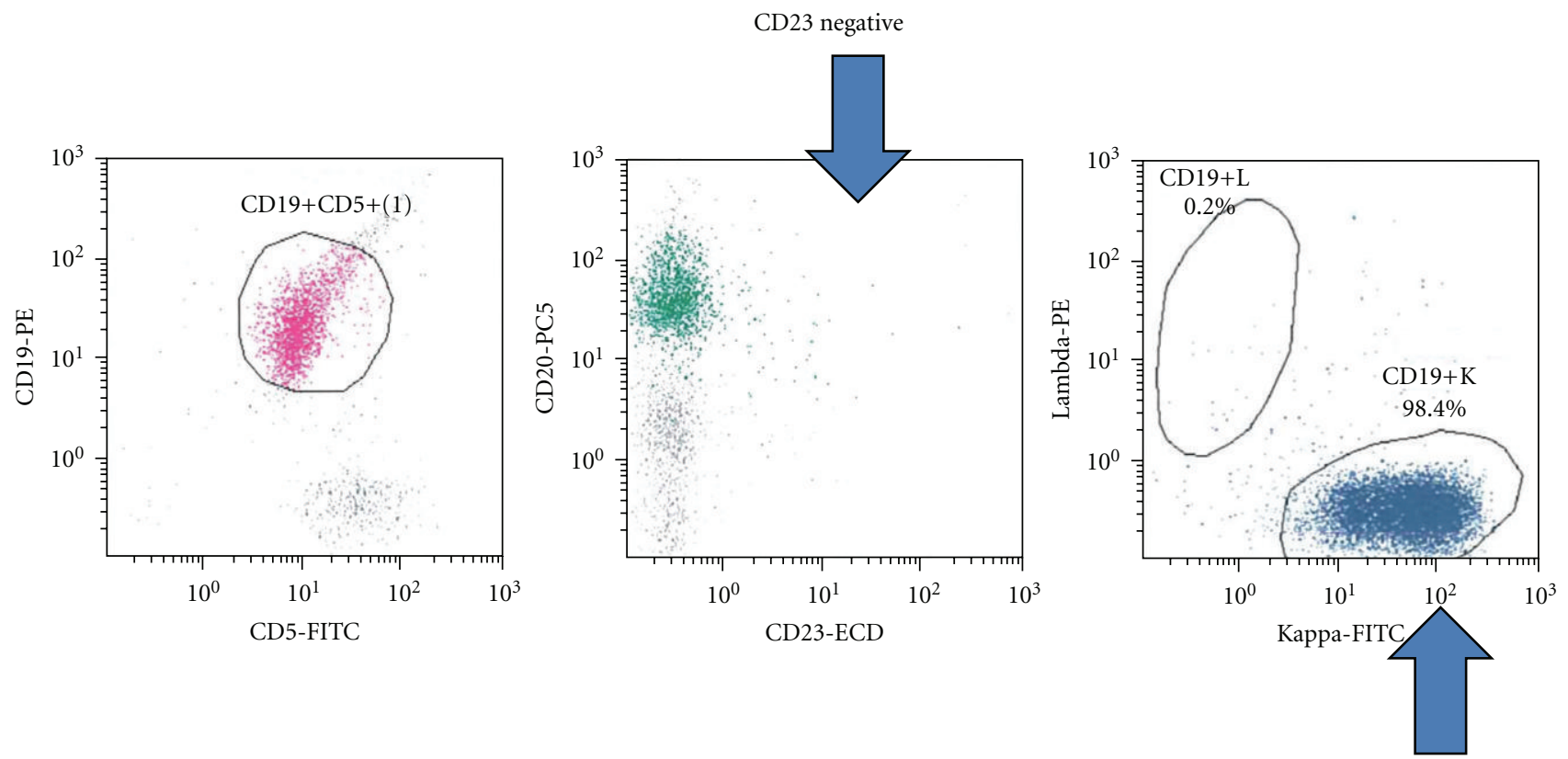

Bright light chain

Figure 12: Flow cytometry of mantle cell lymphoma shows CD5 positive B cells which are also brightly positive for CD20 and kappa light chain and negative for CD23. 
some B lymphocytes. It is useful in the evaluation of marginal zone lymphoma as it may be expressed on the neoplastic lymphoid cells. Extra caution should be taken in evaluation of CD43 in gastrointestinal tissue as normal B cell in these areas (Peyer's patches) might be positive for CD43 [40].

$B C L-2$. The BCL-2 gene, located at chromosome 18q21, encodes an inner mitochondrial membrane protein that prevents apoptosis. Translocation of this gene with the $\operatorname{IgH}$ chain gene at $14 \mathrm{q} 32$ is the most common translocation seen in FLs. This leads to overexpression of the bcl-2 protein with the highest percentage of cases seen in grade-1FL. Since reactive germinal center cells do not express bcl-2, paraffin block IHC for this protein is most useful in the differential diagnosis of FL from follicular hyperplasia. However, bcl2 protein expression is not restricted to FLs or B cells and so expression of this protein alone must not be taken as evidence of a follicular lymphoma.

$B C L-6$. This protein is a zinc finger transcription factor and acts as a sequence-specific repressor of transcription. It is expressed in germinal center derived $\mathrm{B}$ cells and can be seen in normal germinal centers, follicular lymphoma, and a subset of diffuse large B cell lymphoma.

Cyclin D1. The product of CCND1 (located at chromosome 11q13) is involved in cell cycle progression. Translocation involving cyclin $\mathrm{D} 1$ and the $\operatorname{IgH}$ chain $\mathrm{t}(11 ; 14)(\mathrm{q} 13 ; \mathrm{q} 32)$ is present in nearly all MCL. Overexpression of cyclin D1 has been seen in the majority of cases even if the translocation is not detectable. With the rare exception of some cases of hairy cell leukemia, prolymphoctyic leukemia, and plasma cell disorders, expression of cyclin D1 is specific for MCL. Recently SOX11 is identified as another specific marker for MCLs [30].

Assessment of Clonality. For B cell malignancies, clonality can be identified by demonstrating light chain restriction of the immunoglobulin protein or PCR for IgH chain rearrangement. B cells normally express kappa and lambda light chains in a ratio of 2-3:1. A clonal expansion can be identified by a marked predominance of either kappa or lambda light chain. Light chain evaluation is typically performed via flow cytometry, immunohistochemical staining, or in situ hybridization staining. Determining the sample clonality is necessary in cases in which a reactive process cannot be ruled out on the basis of morphologic or immunophenotypic analysis alone as commonly encountered with ENMZLs.

Molecular Genetics/Cytogenetics. Molecular genetic techniques can be helpful in assessing clonality when the morphology and immunophenotype is inconclusive. Southern blot analysis or polymerase chain reaction (PCR) to detect rearrangements of the immunoglobulin gene can be used. The demonstration of a dominant rearrangement of the immunoglobulin gene is indicative of a clonal process. PCR testing has several advantages over southern blot analysis, including increased sensitivity, requirement for smaller amounts of clinical sample, and a rapid turnaround time. Documentation of clonality is especially important in marginal zone lymphomas due to the lack of a specific immunophenotype. Currently a standardized IgH PCR using primers sets from BIOMED-2 consortium is widely used (Figure 13). This standardized assay has far less false negative and false positive results compared to previous assays [41, 42].

Chromosomal translocations are common in lymphoproliferative disorders and can therefore provide useful markers of malignancy. The finding of particular translocations can help confirm a diagnosis (such as IgH-Cyclin D1 in MCL) (Figure 14). Translocation of IgH-Cyclin D1 $\mathrm{t}(11,14)(\mathrm{q} 13 ; \mathrm{q} 32)$ is the hallmark of MCL which results in overexpression of the cyclin D1 protein [43]. The classic cytogenetic method for detecting translocations requires fresh tissue and isolation of viable cells for karyotyping. Molecular genetic methods such as PCR or FISH can be successfully applied to paraffin blocks, thus alleviating the need for fresh tissue. However, genetic testing is only required in a limited number of cases for diagnostic purposes. Requirement for prognostic genetic assays changes with time and availability of new treatment modalities.

CLL/SLL is considered an indolent lymphoma with a variable clinical course. Prognosis is based on clinical staging of the patient, chromosomal aberrations, immunoglobulin gene mutational status, and microRNA expression. Chromosomal aberrations are seen in over $80 \%$ of CLL/SLL cases and thus the current FISH panel for CLL is recommended over conventional chromosomal analysis. Del (17p) or mutated p53 gene is seen in $5-10 \%$ of cases and portends to the poorest prognosis. Currently, analysis of this aberration, in conjunction with stage and performance status, determines first line therapy. Isolated deletion of 13q14.3 is associated with a more favorable prognosis $[4,9,10]$.

Due to the lack of a specific immunophenotype, much research has been placed on finding genetic aberrations specific for MZL. Chromosomal changes commonly seen in ENMZL include trisomy 3, trisomy 18 , and $\mathrm{t}(11 ; 18)$ (q21;q21). The frequency of the specific genetic aberrations vary amongst anatomic sites with some reports finding up to half of the cases of intestinal and lung ENMZL containing the $t(11 ; 18)$, with less frequency seen in other sites. In gastric ENMZL $t(11 ; 18)(\mathrm{q} 21 ; \mathrm{q} 21)$ is associated with resistance to H.Pylori eradication therapy. Translocation $(11 ; 18)(\mathrm{q} 21 ; \mathrm{q} 21)$ is detected in $30-35 \%$ of gastric MZLs and causes the formation of the fusion gene API2-MALT1. This translocation is also associated with BCL10 protein accumulation within the nucleus of neoplastic cells that can be detected in paraffin sections of these tumors [24]. In addition to resistance to antibiotic therapy, $t(11 ; 18)$ is also associated with a greater potential for local infiltration and distant spread. In the pediatric and young adult population similar chromosomal aberrations were noted but with decreased frequency [45]. Additional translocations which are specific for MZL are typically present in a lesser number of cases and include: $\mathrm{t}(1 ; 14)(\mathrm{p} 22 ; \mathrm{q} 32), \mathrm{t}(14 ; 18)(\mathrm{q} 32 ; \mathrm{q} 21)$, and $\mathrm{t}(3 ; 14)(\mathrm{p} 14 ; \mathrm{q} 32)$ - IGH translocated to BCL10, MALT1 and FOXP1, and $\mathrm{t}(\mathrm{X} ; 14)(\mathrm{p} 11.4 ; \mathrm{q} 32.33)$ which is associated 


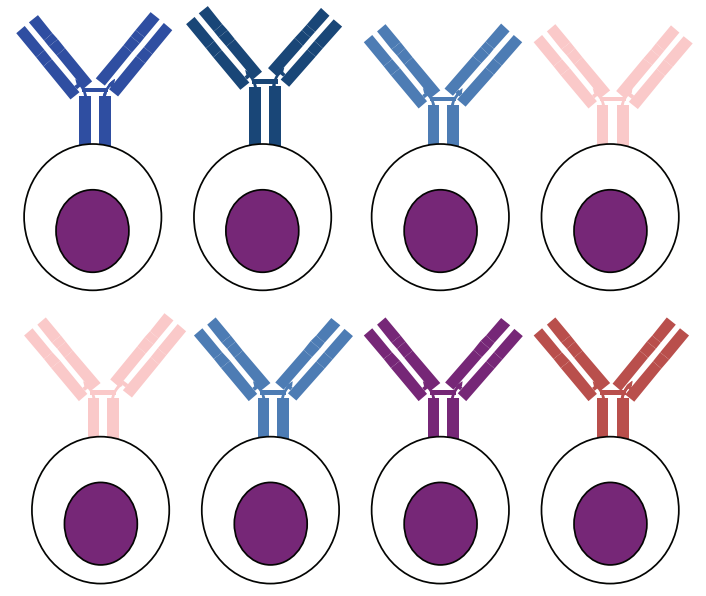

(a)
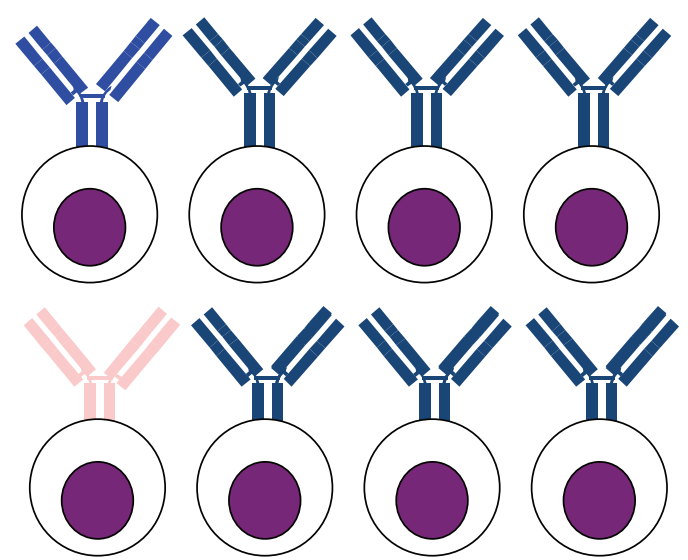

(d)

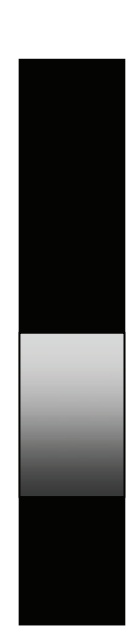

(b)

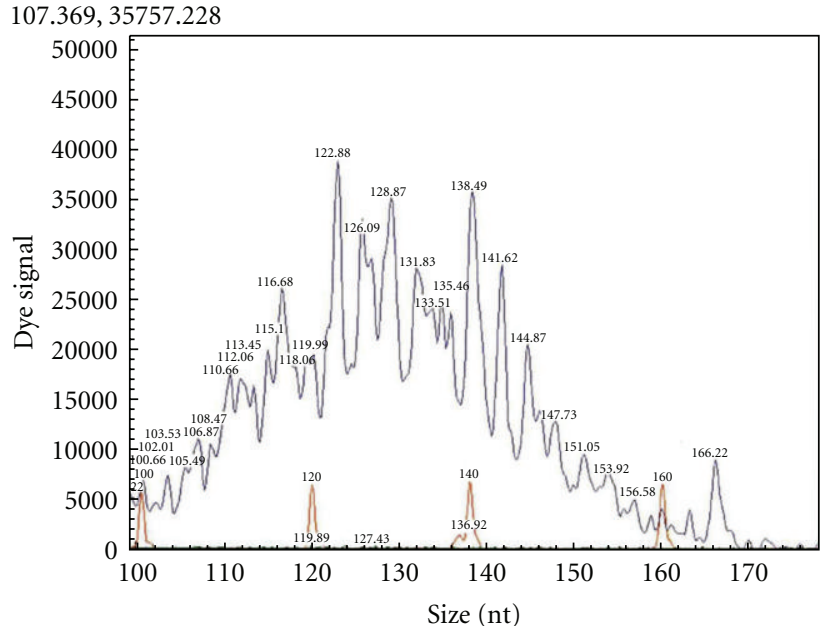

(c)

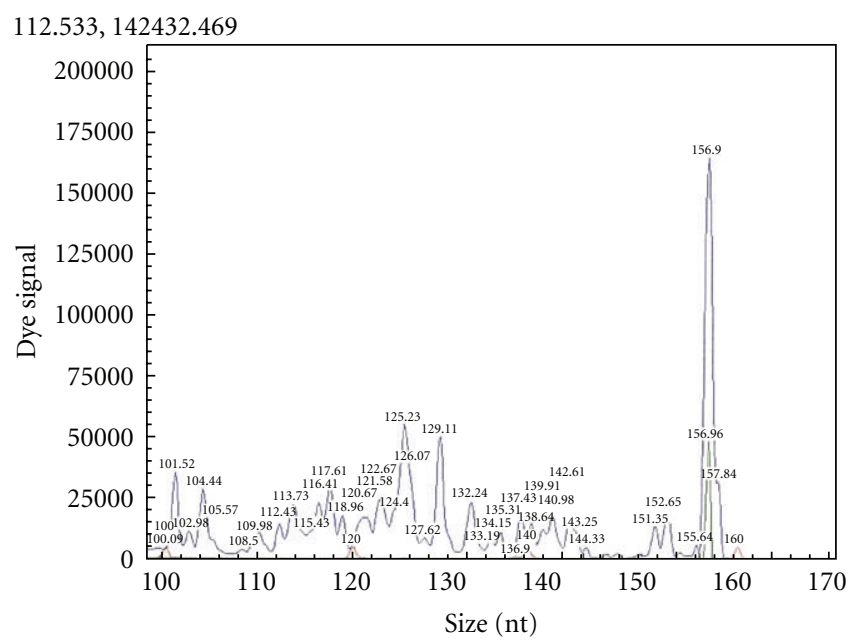

(f)

FIGURE 13: Clonality assessment in B cell lymphoma. In a normal or reactive condition, B cells are composed of heterogeneous populations of B cells expression polyclonal immunoglobulin (heavy and light chain) (a). PCR assay will show different size (smear on the gel) (b) or Gaussian distribution of peaks (c). In a clonal expansion process, there is predominance of one population of B cells with monotypic immunoglobulin (d). PCR assay demonstrates a single band on gel (e) or a predominant peak (f).

with previous autoimmune disorders and involvement of the GPR34 gene [46].

A recent report compared the copy-number abnormalities in lymphoplasmacytic lymphoma, NMZL, SMZL, and ENMZL. There were a number of shared abnormalities including gains of chromosome 3,12, and 18 seen in all lymphomas [47]. They also found that del 17p13.3-p12TP53 gene occurred in 14\% of SMZL and was not seen in NMZL or ENMZL. SMZL also demonstrated a higher frequency of del 7q32.1-q33 (26\%) when compared to lymphoplasmacytic lymphoma and ENMZL and SMZL cases with loss of $17 \mathrm{p}$ and $8 \mathrm{p}$ portending to a decreased outcome.

A majority of follicular lymphoma cases (approximately $85 \%)$ have the chromosomal translocation $\mathrm{t}(14 ; 18)$ (q32; $\mathrm{q} 21)$ which involves the BCL2 gene and the immunoglobulin heavy chain. A minority of follicular lymphoma cases show
TABle 3: Practical fluorescent in situ hybridization studies (FISH) for differential diagnosis of small B cell lymphoma.

\begin{tabular}{lc}
\hline Diagnosis & FISH \\
\hline CLL/SLL & 11, 12q, 13q,17p, probes \\
MZL & MALT1 break apart probe \\
& API2/MALT1 fusion probe \\
FCL & IgH/CCND1 fusion probe \\
FL & IgH/BCL2 fusion probe \\
\hline
\end{tabular}

lack of $\mathrm{t}(14 ; 18)$ and are associated with more frequent 3q27/BCL6 rearrangements, CD10 negativity, MUM1 positivity, increased BCL-XL expression, and an overall molecular phenotype of a late germinal center B-cell stage [34, 35]. Useful clinical FISH studies are summarized in Table 3. 


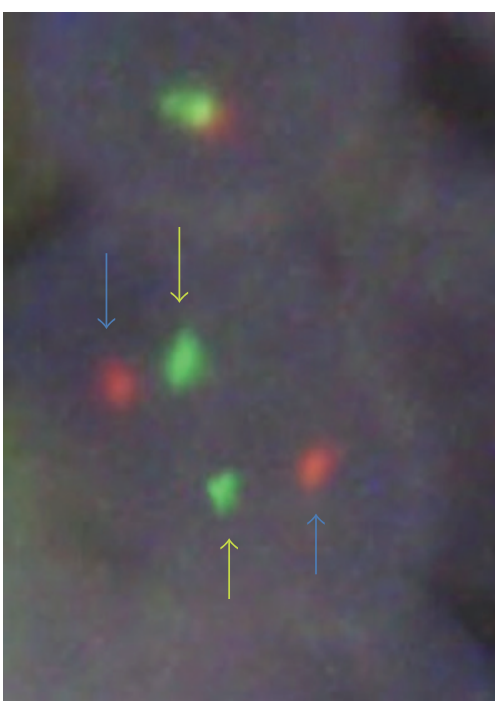

(a)

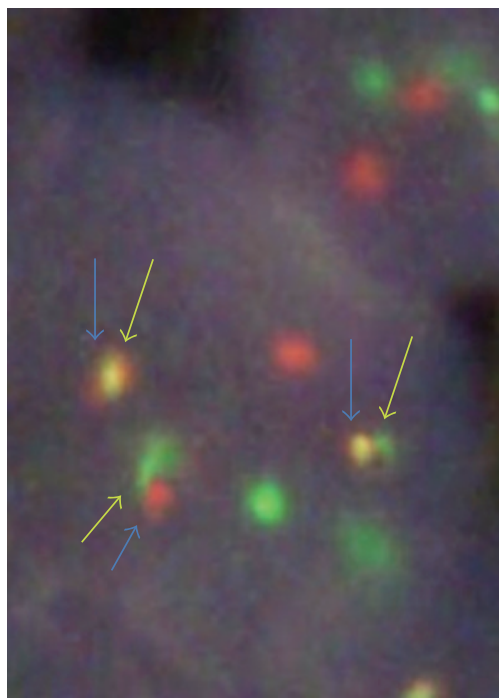

(b)

FIGURE 14: Representative result of interphase fluorescent in situ hybridization (FISH) using fusion probes in mantle cell lymphoma. A normal nucleus shows two separate signals for IgH-green and CYCLIN D-1-orange (a). A nucleus which harbors $\mathrm{t}(11,14)$ translocation shows overlapping (yellow) and adjacent signals (b).

High-throughput technologies allow profiling of DNA (olio array CGH, SNP array), RNA (transcriptome, exome), and microRNA. This is supplanted with next generation sequencing methods (NGS) which allow fast and detailed sequencing. Many interesting and exciting new markers are found in lymphomas using these methods. Two recent studies report L265P somatic mutations in the MYD88 gene in majority of Waldenstrom's macroglobulinemia cases, including non-IgM secreting LPLs. This mutation was not seen in plasma cell myeloma cases which included IgM secreting myeloma cases $[48,49]$. Thus, this mutation may be useful in the differential diagnosis of LPL versus marginal zone lymphoma and plasma cell myeloma. Mutations in SF3B1 (part of splicosome machinery) were found in up to 10$15 \%$ of patients with CLL and is associated more aggressive disease [50, 51]. High frequency of MLL2 mutation has been reported in follicular lymphoma [52]. As applications of these methods become affordable in clinical laboratory, and the target markers are validated, we can utilize them for diagnostic or prognostic purpose.

Ideally a final report should include morphologic, immunophenotypic, and molecular studies. Although part of these studies might be performed outside of original pathologist laboratory; a final summary incorporating all the findings should be issued. An example is illustrated in the Supplementary Material of Figure 15 available online at doi: $10.1155 / 2012 / 346084$.

In summary, accurate diagnosis of most mature small B cell lymphomas can be achieved with a meticulous morphologic evaluation and a concise immunohistochemical panel. Cytogenetic molecular studies may be used to evaluate for chromosomal aberrations which contain diagnostic, prognostic, and therapeutic implications.

\author{
Abbreviations \\ CLL: Chronic lymphocytic leukemia \\ SLL: $\quad$ Small lymphocytic lymphoma \\ ENMZL: Extra nodal marginal zone lymphoma \\ NMZL: Marginal zone lymphoma \\ SMZL: Splenic marginal zone lymphoma \\ FL: $\quad$ Follicular lymphoma \\ MCL: $\quad$ Mantle cell lymphoma \\ LPL: Lymphoplasmacytic lymphoma \\ FISH: $\quad$ Fluorescent in situ hybridization \\ PCR: Polymerase chain reaction.
}

\section{References}

[1] E. S. Jaffe, N. L. Harris, H. Stein, and P. G. Isaacson, "Classification of lymphoid neoplasms: the microscope as a tool for disease discovery," Blood, vol. 112, no. 12, pp. 4384-4399, 2008.

[2] S. H. Swerdlow, E. Campo, J. N. L Harris et al., The World Health Organization Classification of Hematopoietic and Lymphoid Tissue, IARC, Lyon, France, 4th edition, 2008.

[3] E. S. Jaffe, "The 2008 WHO classification of lymphomas: implications for clinical practice and translational research," Hematology American Society Hematology Educational Program, pp. 523-531, 2009.

[4] E. D. Hsi, "Pathologic and molecular genetic features of chronic lymphocytic leukemia," Seminars in Oncology, vol. 39, no. 1, pp. 74-79, 2012.

[5] D. Rossi, E. Sozzi, A. Puma et al., "The prognosis of clinical monoclonal B cell lymphocytosis differs from prognosis of Rai 0 chronic lymphocytic leukaemia and is recapitulated by biological risk factors," British Journal of Haematology, vol. 146, no. 1, pp. 64-75, 2009. 
[6] J. L. Frater, K. F. McCarron, J. P. Hammel et al., "Typical and atypical chronic lymphocytic leukemia differ clinically and immunophenotypically," American Journal of Clinical Pathology, vol. 116, no. 5, pp. 655-664, 2001.

[7] M. Ponzoni, C. Doglioni, and F. Caligaris-Cappio, "Chronic lymphocytic leukemia: the pathologist's view of lymph node microenvironment," Seminars in Diagnostic Pathology, vol. 28, no. 2, pp. 161-166, 2011.

[8] D. Rossi and G. Gaidano, "Richter syndrome: molecular insights and clinical perspectives," Hematological Oncology, vol. 27, no. 1, pp. 1-10, 2009.

[9] H. Döhner, S. Stilgenbauer, A. Benner et al., "Genomic aberrations and survival in chronic lymphocytic leukemia," New England Journal of Medicine, vol. 343, no. 26 I, pp. 1910-1916, 2000.

[10] G. Dighiero, "Unsolved issues in CLL biology and management," Leukemia, vol. 17, no. 12, pp. 2385-2391, 2003.

[11] M. Dal-Bo, I. Del Giudice, R. Bomben et al., "B-cell receptor, clinical course and prognosis in chronic lymphocytic leukaemia: the growing saga of the IGHV3 subgroup gene usage," British Journal of Haematology, vol. 153, no. 1, pp. 314, 2011.

[12] T. J. Molina, P. Lin, S. H. Swerdlow, and J. R. Cook, "Marginal zone lymphomas with plasmacytic differentiation and related disorders," American Journal of Clinical Pathology, vol. 136, no. 2, pp. 211-225, 2011.

[13] H. K. Müller-Hermelink, "Genetic and molecular genetic studies in the diagnosis of B-cell lymphomas: marginal zone lymphomas," Human Pathology, vol. 34, no. 4, pp. 336-340, 2003.

[14] E. Zucca, F. Bertoni, A. Stathis, and F. Cavalli, "Marginal zone lymphomas," Hematology/Oncology Clinics of North America, vol. 22, no. 5, pp. 883-901, 2008.

[15] R. J. Bende, F. Van Maldegem, and C. J. M. Van Noesel, "Chronic inflammatory disease, lymphoid tissue neogenesis and extranodal marginal zone B-cell lymphomas," Haematologica, vol. 94, no. 8, pp. 1109-1123, 2009.

[16] P. J. Kurtin, "Marginal zone B cells, monocytoid B cells, and the follicular microenvironment: determinants of morphologic features in a subset of low-grade B-cell lymphomas," American Journal of Clinical Pathology, vol. 114, no. 4, pp. 505$508,2000$.

[17] F. Bertoni and E. Zucca, "Delving deeper into MALT lymphoma biology," Journal of Clinical Investigation, vol. 116, no. 1, pp. 22-26, 2006.

[18] P. G. Isaacson and M. Q. Du, "MALT lymphoma: from morphology to molecules," Nature Reviews Cancer, vol. 4, no. 8, pp. 644-653, 2004.

[19] E. S. Jaffe, "Common threads of mucosa-associated lymphoid tissue lymphoma pathogenesis: from infection to translocation," Journal of the National Cancer Institute, vol. 96, no. 8, pp. 571-573, 2004.

[20] P. G. Isaacson and M. Q. Du, "Gastrointestinal lymphoma: where morphology meets molecular biology," Journal of Pathology, vol. 205, no. 2, pp. 255-274, 2005.

[21] J. Parsonnet and P. G. Isaacson, "Bacterial Infection and MALT Lymphoma,” New England Journal of Medicine, vol. 350, no. 3, pp. 213-215, 2004.

[22] A. J. M. Ferreri, R. Dolcetti, M. Q. Du et al., "Ocular adnexal MALT lymphoma: an intriguing model for antigen-driven lymphomagenesis and microbial-targeted therapy," Annals of Oncology, vol. 19, no. 5, pp. 835-846, 2008.

[23] A. J. Ferreri, S. Govi, and E. Pasini, "Chlamydophila Psittaci eradication with Doxycycline as first-fine targeted therapy for ccular adnexae lymphoma: final results of an international Phase II trial," Journal of Clinical Oncology, vol. 30, no. 24, pp. 2988-2994, 2012.

[24] M. A. Piris, A. Arribas, and M. Mollejo, "Marginal zone lymphoma," Seminars in Diagnostic Pathology, vol. 28, no. 2, pp. 135-145, 2011.

[25] A. Dogan and P. G. Isaacson, "Splenic marginal zone lymphoma," Seminars in Diagnostic Pathology, vol. 20, no. 2, pp. 121-127, 2003.

[26] E. Ruiz-Ballesteros, M. Mollejo, A. Rodriguez et al., "Splenic marginal zone lymphoma: proposal of new diagnostic and prognostic markers identified after tissue and cDNA microarray analysis," Blood, vol. 106, no. 5, pp. 1831-1838, 2005.

[27] P. Lin, T. J. Molina, J. R. Cook, and S. H. Swerdlow, "Lymphoplasmacytic lymphoma and other non-marginal zone lymphomas with plasmacytic differentiation," American Journal of Clinical Pathology, vol. 136, no. 2, pp. 195-210, 2011.

[28] P. Lin, A. Mansoor, C. Bueso-Ramos, S. Hao, R. Lai, and L. J. Medeiros, "Diffuse large B-cell lymphoma occurring in patients with lymphoplasmacytic lymphoma/Waldenström macroglobulinemia: clinicopathologic features of 12 cases," American Journal of Clinical Pathology, vol. 120, no. 2, pp. 246253, 2003.

[29] S. H. Swerdlow and M. E. Williams, "From centrocytic to mantle cell lymphoma: a clinicopathologic and molecular review of 3 decades," Human Pathology, vol. 33, no. 1, pp. 7-20, 2002.

[30] A. Mozos, C. Royo, E. Hartmann et al., "SOX11 expression is highly specific for mantle cell lymphoma and identifies the cyclin D1-negative subtype," Haematologica, vol. 94, no. 11, pp. 1555-1562, 2009.

[31] E. Campo, "Genetic and molecular genetic studies in the diagnosis of B-cell lymphomas I: mantle cell lymphoma, follicular lymphoma, and Burkitt's lymphoma," Human Pathology, vol. 34, no. 4, pp. 330-335, 2003.

[32] E. Leich, G. Ott, and A. Rosenwald, "Pathology, pathogenesis and molecular genetics of follicular NHL," Best Practice and Research, vol. 24, no. 2, pp. 95-109, 2011.

[33] W. Klapper, "Pathobiology and diagnosis of follicular lymphoma," Seminars in Diagnostic Pathology, vol. 28, no. 2, pp. 146-160, 2011.

[34] R. J. Bende, L. A. Smit, and C. J. M. van Noesel, "Molecular pathways in follicular lymphoma," Leukemia, vol. 21, no. 1, pp. 18-29, 2007.

[35] E. Leich, I. Salaverria, S. Bea et al., "Follicular lymphomas with and without translocation $\mathrm{t}(14 ; 18)$ differ in gene expression profiles and genetic alterations," Blood, vol. 114, no. 4, pp. 826834, 2009.

[36] E. S. Jaffe, P. M. Banks, B. Nathwani, J. Said, and S. H. Swerdlow, "Recommendations for the reporting of lymphoid neoplasms: a report from the Association of Directors of Anatomic and Surgical Pathology. The ad hoc committee on reporting of lymphoid neoplasms," Human Pathology, vol. 33, no. 11, pp. 1064-1068, 2002.

[37] C. F. Garcia and S. H. Swerdlow, "Best practices in contemporary diagnostic immunohistochemistry panel approach to hematolymphoid proliferations," Archives of Pathology and Laboratory Medicine, vol. 133, no. 5, pp. 756-765, 2009.

[38] C. R. Taylor, "IHC and the WHO classification of lymphomas: cost effective immunohistochemistry using a deductive reasoning "decision tree" approach," Applied Immunohistochemistry and Molecular Morphology, vol. 17, no. 5, pp. 366-374, 2009.

[39] C. R. Taylor, "The WHO classification of lymphomas: costeffective immunohistochemistry using a deductive reasoning 
"decision tree" approach: part II: the decision rree approach: diffuse patterns of proliferation in lymph nodes," Applied Immunohistochemistry and Molecular Morphology, vol. 17, no. 6, pp. 470-482, 2009.

[40] P. S. Lee, D. Beneck, J. Weisberger, and W. Gorczyca, "Coexpression of CD43 by benign B cells in the terminal ileum," Applied Immunohistochemistry and Molecular Morphology, vol. 13, no. 2, pp. 138-141, 2005.

[41] S. H. Swerdlow, "Genetic and molecular genetic studies in the diagnosis of atypical lymphoid hyperplasias versus lymphoma," Human Pathology, vol. 34, no. 4, pp. 346-351, 2003.

[42] J. J. M. van Dongen, A. W. Langerak, M. Brüggemann et al., "Design and standardization of PCR primers and protocols for detection of clonal immunoglobulin and T-cell receptor gene recombinations in suspect lymphoproliferations: report of the BIOMED-2 concerted action BMH4-CT98-3936," Leukemia, vol. 17, no. 12, pp. 2257-2317, 2003.

[43] F. Bertoni, A. Rinaldi, E. Zucca, and F. Cavalli, "Update on the molecular biology of mantle cell lymphoma," Hematological Oncology, vol. 24, no. 1, pp. 22-27, 2006.

[44] H. Ye, A. Dogan, L. Karran et al., "BCL 10 expression in normal and neoplastic lymphoid tissue: nuclear localization in MALT lymphoma," American Journal of Pathology, vol. 157, no. 4, pp. 1147-1154, 2000.

[45] K. A. Rizzo, B. Streubel, S. Pittaluga et al., "Marginal zone lymphomas in children and the young adult population; Characterization of genetic aberrations by FISH and RT-PCR," Modern Pathology, vol. 23, no. 6, pp. 866-873, 2010.

[46] C. Baró, B. Espinet, M. Salido et al., "FOXP1 status in splenic marginal zone lymphoma: a fluorescence in situ hybridization and immunohistochemistry approach," Histology and histopathology, vol. 24, no. 11, pp. 1399-1404, 2009.

[47] E. Braggio, A. Dogan, J. J. Keats et al., "Genomic analysis of marginal zone and lymphoplasmacytic lymphomas identified common and disease-specific abnormalities," Modern Pathology, vol. 25, no. 5, pp. 651-660, 2012.

[48] S. P. Treon, L. Xu, G. Yang et al., "MYD88 L265P somatic mutation in Waldenström's macroglobulinemia," New England Journal of Medicine, vol. 367, no. 9, pp. 826-833, 2012.

[49] N. Gachard, M. Parrens, I. Soubeyran et al., "IGHV gene features and MYD88 L265Pmutation separate the three marginal zone lymphoma entities and Waldenström macroglobulinemia/lymphoplasmacytic lymphomas," Leukemia. In press.

[50] V. Quesada, L. Conde, N. Villamor et al., "Exome sequencing identifies recurrent mutations of the splicing factor SF3B1 gene in chronic lymphocytic leukemia," Nature Genetics, vol. 44, no. 1, pp. 47-52, 2012.

[51] L. Wang, M. S. Lawrence, Y. Wan et al., "SF3B1 and other novel cancer genes in chronic lymphocytic leukemia," New England Journal of Medicine, vol. 365, no. 26, pp. 2497-2506, 2011.

[52] R. D. Morin, M. Mendez-Lago, A. J. Mungall et al., "Frequent mutation of histone-modifying genes in non-Hodgkin lymphoma," Nature, vol. 476, no. 7360, pp. 298-303, 2011. 


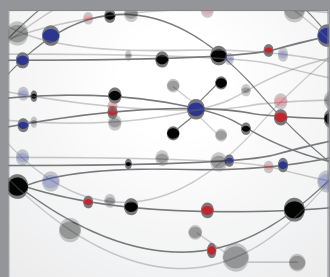

The Scientific World Journal
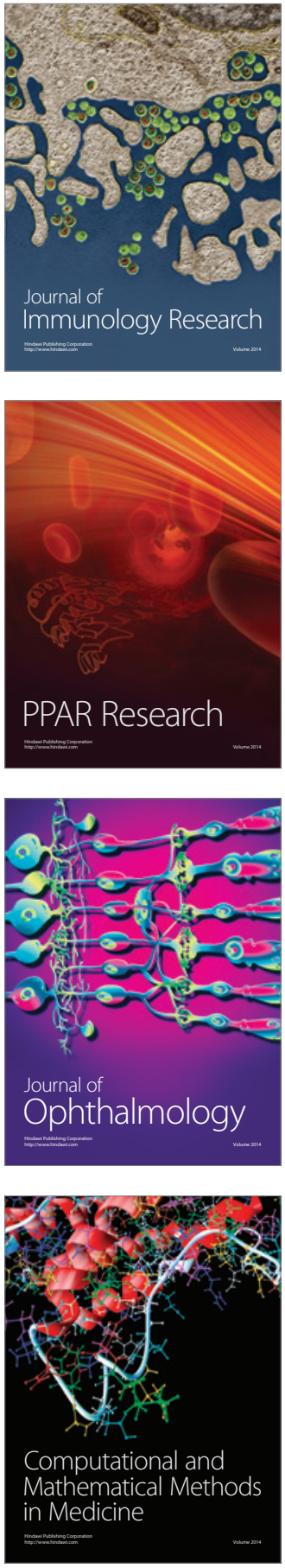

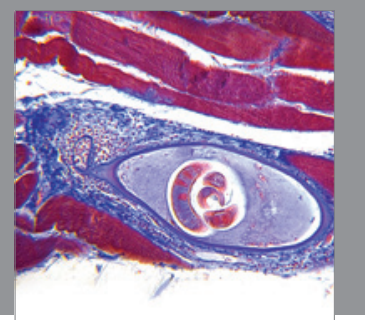

Gastroenterology

Research and Practice
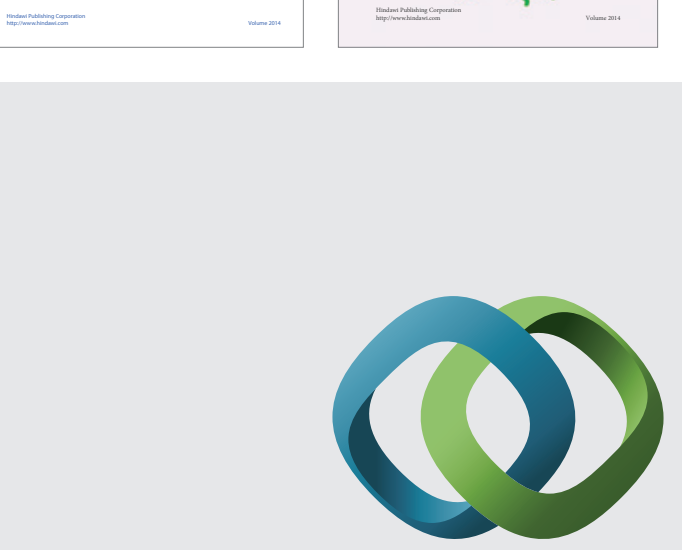

\section{Hindawi}

Submit your manuscripts at

http://www.hindawi.com
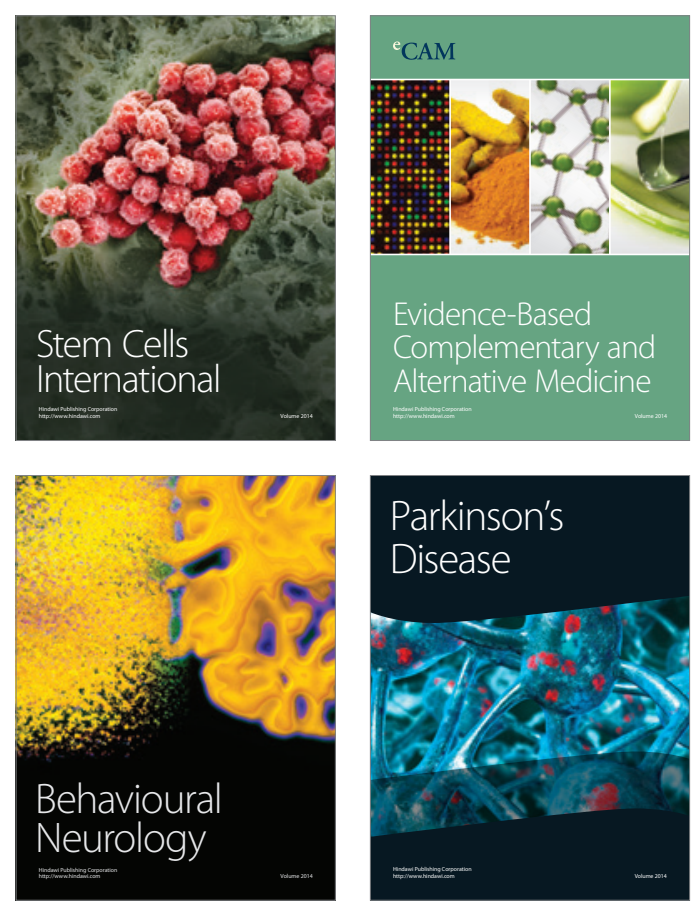

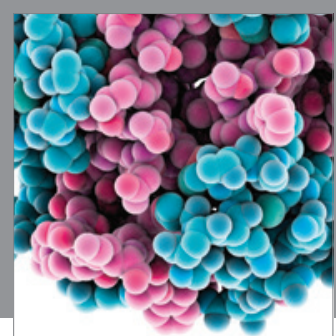

Journal of
Diabetes Research

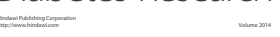

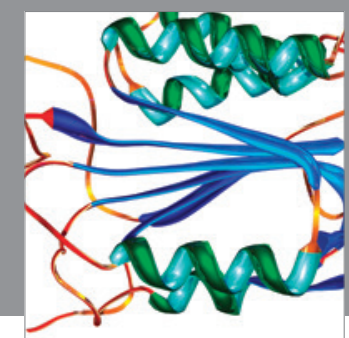

Disease Markers
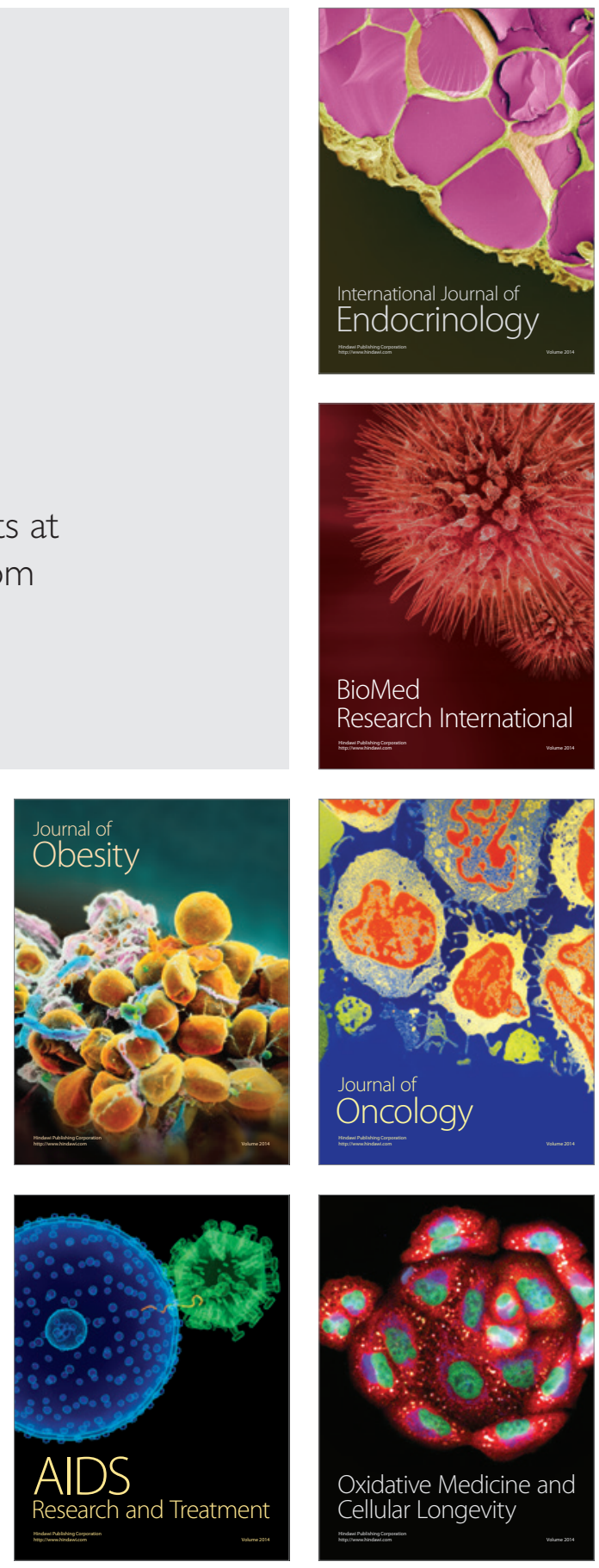